\title{
BREVE LEITURA DO ESPAÇO-TEMPO NAS PASSAGENS DE WALTER BENJAMIN: CONTRIBUIÇÕES PARA COMPREENSÃO GEOGRÁFICA DO CAPITALISMO ${ }^{1}$
}

\author{
BRIEF READING OF SPACE-TIME IN PASSAGEWAYS OF WALTER BENJAMIN: \\ CONTRIBUTIONS TO GEOGRAPHICAL UNDERSTANDING OF CAPITALISM
}

\author{
BREVE LECTURA DEL ESPACIO-TIEMPO EN LOS PASAJES \\ DE WALTER BENJAMIN: CONTRIBUCIONES PARA LA \\ COMPRENSIÓN GEOGRÁFICA DEL CAPITALISMO
}

\author{
Wagnervalter Dutra Júnior - Universidade do Estado da Bahia - Caetité - Bahia - Brasil \\ wagnervalter@yahoo.com.br
}

\begin{abstract}
Resumo
As passagens foram se estabelecendo nas ruas de Paris a partir de meados do século XIX, paralelo à ampliação da produção e circulação de mercadorias na capital francesa. As exposições universais da produção industrial, bem como a utilização do ferro e do vidro na arquitetura e construções, datam da mesma época e têm como pano de fundo o mesmo processo de intensificação da materialidade capitalista na Europa. Walter Benjamin elabora uma densa pesquisa a respeito da estruturação do espaço-tempo subjacente ao processo que estabelece as passagens e, concomitantemente, à haussmannização das ruas de Paris, processo que tem relação direta com o estabelecimento da centralidade da mercadoria na sociedade francesa e com a ampliação da alienação. A reflexão apresentada busca levantar a possibilidade de resgatar a leitura do espaço-tempo que Walter Benjamin realiza em Passagens como forma de auxiliar na compreensão geográfica do capitalismo. Palavras-chave: capital, mercadoria, fantasmagoria, alienação, Paris.
\end{abstract}

\section{Abstract}

The passageways were settling in the streets of Paris since mid-nineteenth century, parallel to the expansion of production and circulation of commodity in the French capital. The universal exhibition of industrial production and the use of iron and glass in the architecture and buildings, are from the same time and has as backdrop the same process of intensification of the capitalist materiality in Europe. Walter Benjamin develops a dense research about the structure of the space-time underlying the process that establishes the passagesway and concomitantly the haussmannization of the streets of Paris, process that has direct relation to the establishment of the centrality of commodity in French society, as well as with the enlargement of alienation. The reflection presented seeks to raise the possibility of recovering the reading of space-time that Walter Benjamin accomplishes in the Passageways as a way to assist in the geographical comprehension of capitalism.

Keywords: capital, commodity, phantasmagoria, alienation, Paris.

\section{Resumen}

Los pasajes fueron instalándose en las calles de París desde mediados del siglo XIX, paralelamente a la expansión de la producción y circulación de mercaderías en la capital francesa. Las exposiciones universales de la producción industrial, así como la utilización del hierro y del vidrio en la arquitectura y en las construcciones, datan de la misma época y tienen como telón de fondo el mismo proceso de intensificación y materialidad capitalista en Europa. Walter Benjamin hace una investigación densa acerca de la estructuración del espacio- 
tiempo subyacente al proceso que establece los pasajes $y$, al mismo tiempo, la haussmannización de las calles de París, proceso que tiene relación directa con el establecimiento de la centralidad de la mercadería en la sociedad francesa, así como con la expansión de la alienación. La presente reflexión busca incentivar la posibilidad de rescatar la lectura del espacio-tiempo que Walter Benjamin realiza en Pasajes como una forma de ayudar en la comprensión geográfica del capitalismo.

Palabras-clave: capital, mercadería, fantasmagoría, alienación, París.

\section{Introdução: as passagens parisienses em Walter Benjamin}

O objetivo deste artigo é refletir acerca da contribuição que a análise de Walter Benjamin sobre as passagens parisienses traz para a reflexão sobre o espaço-tempo e a geografia produzida no âmbito do sistema capitalista.

O estudo sobre as passagens parisienses constitui um denso trabalho de pesquisa por meio do qual Walter Benjamin (2009) pretendia abordar um período histórico - século XIX - em que a capital francesa experimentou um desenvolvimento intenso das relações capitalistas. O projeto não chegou a ser completado, todavia, os arquivos relativos à pesquisa e os textos que sinalizavam os percursos metodológicos, as anotações separadas em arquivos temáticos e indicações do autor foram publicados.

As análises realizadas por Benjamin (2009) são extremamente instrutivas para se entender a produção do espaço-tempo diante das relações capitalistas desenvolvidas no âmbito da modernidade. Nesse sentido, é possível perceber que as passagens criadas em Paris expressam uma geografia peculiar, uma estrutura / dinâmica a expressar as contradições da relação capital x trabalho, posta espaço-temporalmente.

Na introdução à edição alemã, o organizador Rolf Tiedemann (2009) aponta para o que Walter Benjamin buscava compreender em Paris, no século XIX, e o que emergia em seu constructo teórico-metodológico, representado no trabalho das passagens.

O século XIX é o sonho do qual se deve despertar: um pesadelo que pesará sobre o presente enquanto permanecer intacto seu fascínio. As imagens do sonho e o despertar desse sonho comportam-se, segundo Benjamin, como a expressão e a interpretação; para ele, somente a interpretação das imagens dissolveria o fascínio. O despertar benjaminiano visava ao 'genuíno desprendimento de uma época', no duplo sentido da Aufhebung hegeliana: a superação do século XIX em sua preservação, sua 'salvação' para o presente [...] (Tiedemann, 2009 apud Benjamin, 2009, p. 19). 
O capitalismo, nos traços míticos de sua experiência espaçotemporal (Benjamim, 2009), precisaria ser desvendado a partir dos signos e imagens dialéticas que o passado-presente, posto nas apreensões cotidianas apresentadas pelo, agora, onírico, oferecem à dialética espiral da produção da história.

A cultura plasmada na Paris do segundo império, investigada em Passagens, está embebida num conjunto de fetiches comandado pela fantasmagoria central na produção da vida material que pulsa nas ruas de Paris, nas exposições universais, na haussmannização ${ }^{1}$, no Flâneur, no jogo, na moda, na prostituição: a mercadoria que oculta a 'forma-valor' (Marx, 2013).

Como a economia política clássica, que visava justificar a permanência das relações capitalistas ad infinitum (Marx, 2011), a fantasmagoria das passagens, fundamentalmente, em sua aparência e nas relações que proporcionam fluírem no imediato devir homem do homem, guarda o ímpeto da 'naturalização' nas turbulências e no frenesi das ruas parisienses.

Em Passagens, Walter Benjamin (2009) buscava o mistério que se escondia detrás das criações e formas de vida condicionadas pela produção de mercadorias e sua transfiguração na imediatez da presença sensível. Daí sua atenção ao fantasmagórico na cotidianidade e ao brilho envolvente da sociedade produtora de mercadorias, brilho que tem pouca relação com algum tipo de estética idealista, todavia, é diretamente proporcional ao caráter fetichista da mercadoria.

As fantasmagorias das 'imagens do desejo' coletivo e das 'imagens mágicas do século’ são a procura por transfigurar as imperfeições do produto social e da ordem social de produção (Tiedemann apud Benjamin, 2009). A fantasmagoria parece cumprir uma função específica na regulação social mercantil.

Primeiramente, a função da fantasmagoria parece ser uma função de transfiguração: assim as exposições universais transfiguram o valor de troca das mercadorias ao ofuscar o caráter abstrato de suas determinações de valor; assim o colecionador transfigura as coisas ao retirar-lhes o caráter de mercadoria; e assim são transfiguradas a construção em ferro e a arquitetura em vida nas passagens, porque 'o século não conseguiu responder às novas

\footnotetext{
1 Diz respeito ao conjunto de intervenções urbanísticas implantadas em Paris, a partir dos projetos do Barão Haussmann, no período de Napoleão III (Benjamin, 2009).
} 
possibilidades técnicas com uma nova ordem social' (GS V, 1257) [...] O caráter ilusório de tudo o que é novo, graças ao qual esse século [XIX] se apresentava como a modernidade par excellence, completava-se em sua ideia suprema, a ideia de progresso, que Benjamin viu denunciada por Blanqui como 'fantasmagoria da própria história': 'como antiguidade imemorial, que desfila orgulhosa em roupagem de última novidade', como eterno retorno do sempre igual, onde 'a humanidade figura como amaldiçoada' (GS, V, 1256) [...] O elemento transfigurador da fantasmagoria transforma-se em Aufklärung, na ideia 'de que a humanidade estará à mercê do medo mítico enquanto a fantasmagoria ocupar um lugar nela' (Tiedemann apud Benjamin, 2009, p. 24).

A mercadoria e sua fantasmagoria estão diretamente associadas ao contexto do progresso, as formas ideológicas subjacentes clamaram pela continuidade dessa forma pautada na inexorabilidade do próprio progresso. Para não correr o risco da aceitação tácita do que subjaz oculto no progresso, Walter Benjamin procura o que se acoberta sob as máscaras da forma valor e do progresso, em função do seu compromisso com os oprimidos, que, por sua vez, só poderão vir-a-ser enquanto realização que se liberta das amarras do fetichismo (valor / progresso). Nesse sentido, muito além de se colocar, ingenuamente, contrário ao progresso, Walter Benjamin busca, nas imagens dialéticas e no sonho, romper com o futuro enquanto eterno retorno, apresentando-se moderno, o que constitui perigo inerente ao enfrentamento necessário ao progresso.

Ao discutir o fetichismo da mercadoria, Marx (2013) indica que a efetividade da sua produção se oculta em sutilezas metafísicas e argúcias teológicas, todavia, a mercadoria se apresenta efetiva ao homem, que não percebe o que ela oculta, vendo a relação entre as pessoas como se a mesma se efetivasse na aparência de uma relação entre coisas e da coisa como relação entre seres humanos.

Desenvolvendo esse debate, Marx cita exemplos de objetos úteis, como mesa, que, ao se revelar como mercadoria, situada num sistema de troca e constituída socialmente, inicia o que Marx denomina uma espécie de 'dança', perceptível e impalpável, algo que é não sendo. A “[...] essência da produção capitalista deveria ser captada nas formas históricas concretas, nas quais a economia encontra sua expressão cultural" (Tiedemann apud Benjamin, 2009, p. 26). 
Dando sentido à busca benjaminiana em Passagens, a ideia de uma fisiognomonia materialista deveria servir para complementar a teoria marxista, de forma sempre cautelosa, para evitar o risco mítico que o progresso exerceu, até mesmo no marxismo.

Uma mudança dos conceitos de história e historiografia caracteriza a ligação entre os dois esboços do trabalho das Passagens. Sua invectiva polêmica dirige-se contra a ideia de progresso dominante no século XIX. Com a única exceção de Schopenhauer no qual, e não por acaso, o mundo objetivo já carrega o nome de fantasmagoria, as filosofias idealistas tinham feito do progresso a 'assinatura do curso da história em sua totalidade' $(\mathrm{N} \mathrm{13,1)}$, privando-o assim de sua função emancipatória e crítica. Mesmo a confiança de Marx depositada no desenvolvimento das forças produtivas era uma hipóstase do conceito de progresso e deveria parecer insustentável a Benjamin em vista das experiências do século XX. [...] Benjamin exigia já no primeiro esboço das Passagens uma filosofia da história que ultrapassasse em todas as partes a ideologia do progresso, que ele expôs então nas teses sobre a filosofia da história [...] (Tiedemann apud Benjamin, 2009, p. 27).

No livro em análise, a história passada deveria estar fundada na atualidade, calcada na reviravolta dialética do instante ocorrido, e o ocorrido, por seu turno, tornar-se reviravolta dialética, assim, a consciência desperta. A sua pesquisa buscou, partir do século XIX, as formas perdidas para olhar a história de frente, visto que o passado é o possível do futuro no presente. Dessa maneira, o progresso perde a linearidade do evolucionismo e ganha contornos espirais, redimindo-se diante da crítica e da emancipação.

Em razão da visão benjaminiana, conforme Tiedemann (apud Benjamin, 2009), revela-se, metodologicamente, o que Passagens reflete sobre a historiografia materialista: aquilo que se encontra na história - no espaço-tempo - e não foi resgatado por ela é o objeto.

Paris: a capital do século XIX e sua geografia da mercantilização

Ao iniciar a escrita de Passagens (2009), em dois textos (as exposés), datados respectivamente de 1935 e 1939, Walter Benjamin sinalizava o que seria o projeto quando decidiu dedicar-se à leitura sobre Paris e suas passagens. 
Nossa pesquisa procura mostrar como, em consequência dessa representação coisificada da civilização, as formas de vida nova e as novas criações de base econômica e técnica, que devemos ao século XIX, entram no universo de uma fantasmagoria. Tais criações sofrem essa ‘iluminação’ não somente de maneira teórica, por uma transposição ideológica, mas também na imediatez da presença sensível. Manifestam-se enquanto fantasmagorias. (Benjamin, 2009, p. 53).

O autor situa o surgimento das passagens parisienses nos quinze anos subsequentes a 1822 e o comércio têxtil foi o impulso inicial para que as passagens ocupassem as ruas da capital francesa. $\mathrm{O}$ ciclo do capital (D - M - D') é intensificado e os magasins de nouveautés, primeiro tipo de estabelecimento a manter grandes estoques de mercadorias, sendo precursor das lojas de departamentos, começam a integrar os cenários das passagens da capital francesa e suas ruas (Benjamin, 2009).

As passagens põem a cidade como vitrine. A cidade mercantil a serviço da reprodução do capital ganha corpo nas passagens. As mercadorias de luxo expostas diante do fluir dos citadinos exercem fascínio para quem passa. Benjamin (2009) resgata como as passagens são descritas em um Guia Ilustrado de Paris da época:

Estas passagens, uma recente invenção do luxo industrial, são galerias cobertas de vidro e com paredes revestidas de mármore, que atravessam quarteirões inteiros, cujos proprietários se uniram para esse tipo de especulação. Em ambos os lados dessas galerias, que recebem a luz do alto, alinham-se as lojas mais elegantes, de modo que tal passagem é uma cidade, um mundo em miniatura (p. 40).

As conexões que as passagens estabelecem desenham uma clara geografia mercantil, onde a experiência espaço-temporal centrada nos movimentos de circulação do capital vai esculpindo a 'compressão espaçotempo' (Harvey, 2001) da Paris do século XIX, cidade que começa a abrigar os 'mundos' em miniatura das passagens. A realização das exposições universais, paralelas à ampliação das passagens, chega a Paris, cercando-a das relações de troca que a divisão social e territorial do trabalho capitalista mundializava.

O surgimento das passagens tem relação direta com as construções em ferro que se estabeleceram e foram utilizadas pela engenharia e arquitetura na França do século XIX. Os trilhos das ferrovias francesas 
do século XIX põem um duplo caminho: o dos próprios trilhos e o da moldagem e utilização das primeiras peças de ferro, cujas vigas utilizadas na construção civil encontram seu antecessor (Benjamin, 2009).

A funcionalidade da arquitetura e da condição de vitrine das passagens é o paralelo do espaço-tempo da maquinaria da grande indústria. Benjamin (2009) retrata a utopia fourierista impulsionada pela maquinaria, relacionando-a a passagens: "Essa maquinaria feita de seres humanos produz o país das maravilhas, o primevo símbolo do desejo ao qual a utopia de Fourier deu vida" (p. 41), utopia que liberta engrenagens da máquina capitalista transpostas na arquitetura e nos panoramas da cidade luz.

Assim como a arquitetura começa a emancipar-se da arte com a construção de ferro, assim a pintura por sua vez o fez com os panoramas. $\mathrm{O}$ apogeu da difusão dos panoramas coincide com o surgimento das passagens. [...] Os panoramas, que anunciam uma revolução nas relações da arte com a técnica, são ao mesmo tempo expressão de um novo sentimento de vida [...] Nos panoramas, a cidade amplia-se, transformando-se em paisagem, como ela o fará mais tarde e de maneira mais sutil para o flâneur (Benjamin, 2009, p. 42).

Ao lado dos panoramas a fotografia ganha espaço, liberta as possibilidades de ampliação da vista remota do homem, entretanto, não deixa de compor parte da reprodução mercantil capitalista, pois ela incorpora uma mostra especial presente na exposição universal de 1855.

As exposições universais são realizadas nas cidades veículo do fetiche da mercadoria. As passagens são a extensão da exposição universal aos habitantes de Paris, cujas mercadorias começam a peregrinar diante do homem, circundado nos limites da mobilidade do capital e do trabalho.

As exposições universais produzem a impotência do homem e a abstração das suas necessidades (valor de uso) diante do valor de troca.

As exposições universais idealizam o valor de troca das mercadorias. Criam um quadro no qual seu valor de uso passa para segundo plano. Inauguram uma fantasmagoria na qual o homem entrega para divertir-se. A indústria de entretenimento facilita isso elevando-o ao nível da mercadoria. Ele se abandona às suas manipulações ao desfrutar a sua própria alienação e a dos outros. - A entronização da mercadoria e o brilho da distração que a cerca é o tema secreto na arte de Grandville. A isso corresponde a discrepância entre o 
seu elemento utópico e seu elemento cínico. Suas especiosidades na representação de objetos inanimados correspondem àquilo que Marx denomina de 'argúcias teológicas' da mercadoria (Benjamin, 2009, p. 44).

O universo das mercadorias figura realizado na apoteose das exposições universais, possui a concreção de determinar a mercadoria como centro do mundo e Paris a sua capital (Benjamin, 2009).

Também é interessante observar que, paralelamente ao universal mercantil imposto pelas passagens e culminante nas exposições universais, algo ainda haveria de se realizar diante da espacialidade da metrópole capitalista francesa. O movimento do universal não se realiza sem que o particular constitua parte da sua negatividade. Sob Luís Felipe $^{2}$, o intérieur conecta o público e o privado e apaga os rastros da cisão candente da qual a sociedade burguesa se alimenta.

Marx, em As lutas de classe na França (2012), analisou os conflitos que presidiam as classes em movimento e em luta no período de 1830 a 1848, os quais escondiam os interesses das frações da burguesia para mobilizar pequenos burgueses, camponeses e proletários a se posicionarem na Revolução de Fevereiro e abolir os resquícios monárquicos ainda em voga, reafirmando o seu domínio na Revolução de Julho. A república instaurou-se graças à ação, capitulada pela burguesia, dos camponeses e do proletariado, entretanto, apenas fortaleceu a gestão dos negócios comuns da burguesia, tendo em vista que a manobra colocou o Estado nas mãos dos burgueses, mediando os anseios de suas frações distintas. Na prática, a aristocracia financeira e os banqueiros continuaram a reinar, tendo o Estado francês como credor, e as garantias para a burguesia industrial e financista se mantiveram.

Luís Felipe e Guizot - representando a burguesia - estimularam as construções de ferrovias, agradando aos industriais e aos financistas que tinham a certeza de que a produção e circulação bem como as ações das ferrovias e emissão monetária estariam sob o seu controle. O intérieur foi gestado a partir da especificidade histórica em cujo contexto alçava a luta de classes.

\footnotetext{
${ }^{2}$ Foi Rei da França de 1830 até 1848. Na Ideologia Alemã o contexto referencial da Revolução de Julho é esclarecido: refere-se à revolução francesa de julho de 1830, que depôs o Rei Bourbon Carlos X e alçou ao trono Luís Felipe de Orléans, conhecido como "o rei burguês". Seu reinado (a Monarquia de Julho), caracterizado por alterações de caráter liberal na constituição restauracionista de 1814, duraria até a revolução de 1848. (Marx; Engels, 2007, p. 558).
} 
Sob sua proteção [Guizot], a classe dominante faz história ao fazer seus negócios. Ela estimula a construção de ferrovias para melhorar seu capital em ações. Apoia o poder de Luís Felipe como o reino do homem privado que administra seus próprios negócios. Com a revolução de julho [de 1830], a burguesia alcança os objetivos de 1789 (Marx). [...] Para o homem privado, o espaço em que vive se opõe pela primeira vez ao local de trabalho. O primeiro constitui-se com o intérieur. O escritório é seu complemento. O homem privado, que no escritório presta contas à realidade, exige que o intérieur o sustente em suas ilusões. Esta necessidade é tanto mais urgente quanto menos ele cogita estender suas reflexões relativas aos negócios em forma de reflexões sociais. Na configuração de seu mundo privado, reprime ambas. Disso originam-se as fantasmagorias do intérieur. Este representa para o homem privado o universo (Benjamin, 2009, p. 45).

O intérieur integra-se ao mundo da mercadoria, absorvendo o restante do tempo no espaço produzido da casa. O homem, sentado em seu habitat, circula pelas relações mercantis ao produzir seu intérieur no reflexo das relações sociais as quais se encontra subsumido no trabalho e na 'dança' que as mercadorias fazem diante dele.

Deslocado espacialmente dos ditames do capital, numa geograficidade mercantil, mira da sua casa o universo, as exposições universais saem a buscá-lo e integrá-lo no espetáculo esfingético de não se reconhecer, para que, mesmo não se realizando no trabalho, também não se efetive em seu próprio habitat, fechando o ciclo de sua alienação.

Algo inscrito no que Benjamin vê na época do Segundo Império, quando “[...] data a especialização lógica por espécie e por gênero, que perdura ainda na maior parte dos nossos apartamentos”, onde, por exemplo, ficam reservadas "[...] o carvalho e a nogueira maciça para a sala de jantar e para o gabinete de trabalho [...]" (2009b, p. 253). Nesse processo, a casa, o intérieur, se mercantilizam.

Os padrões começam a dominar as ruas e atinge o intérieur. As sutis especificidades do processo de padronização - a repetição requerida pela produção capitalista em seu movimento autovalorativo - no habitat ficam por conta da decoração, das mercadorias que passam a ocupar o intérieur indicando uma diferenciação de classe.

Contudo, o capital requer tal processo em linhas gerais, assim, a haussmannização indica os pressupostos de seu espaço-tempo, podendo-se perceber a mediação entre o intérieur e Haussmann, entre a casa e as ruas de Paris, a serviço da lógica do capital. O espaço-tempo na Paris de Haussmann já está posta na imanência capitalista do mais-valor, a haussmannização e o intérieur são a expressão do meso e do micro cosmo da dominação espaço-temporal cartesiana. 
Tanto na casa (o habitat) quanto nas ruas, o espaço-tempo que importa é a da unicidade do tempo comprimido, que não permite um olhar mais atento que se destine a ver além da suntuosidade das vitrines - do ferro, do vidro e do mármore das passagens - e da condição de autômato dentro do trabalho e fora dele, no deslocamento diante das passagens, até que se esteja em casa, onde o relógio de parede não passa da extensão do relógio de ponto do 'chão da fábrica'.

O que a ditadura da linha reta - expressão utilizada por David Harvey em A condição pós-moderna para se referir ao papel de Haussmann na produção do espaço designado pelo capital, a exemplo de Brasília - tem a ver com esse relógio de parede? A unificação funcional no espaço-tempo daquilo que Mészáros (2007) sinaliza como sendo um dos aspectos mais degradantes da ordem social do capital e que reduz os seres humanos à condição reificada, adequando-os aos limites estreitos da contabilidade do tempo do sistema sociometabólico capitalista: a prisão inevitável a essa contabilidade do tempo como a única possível, extremamente desumanizadora, porém, a única compatível com o sistema do capital. Essa forma social, afirma Mészáros (2007) baseado em Marx, reduz os seres humanos a uma subordinação alienante consubstanciada na equação quantidade e tempo, sob os imperativos vigentes do capital.

A linha reta haussmanniana e o intérieur abrem caminho para a incorporação do trabalho excedente, mas presos na camisa-de-força sufocante da mais-valia (expressão de Mészáros), visando sempre à redução ao mínimo do tempo de trabalho necessário, “[...] de modo a ser manipulada pela contabilidade do tempo não apenas desumanizadora, mas também, em termos históricos, cada vez mais anacrônica, do sistema” (Mészáros, 2007, p. 43). Daí o ímpeto a descartar e mesmo destruir tudo o que não possa ser lucrativo.

A haussmannização tinha como perspectiva os longos traçados das ruas, e Benjamin (2009b) vê esse ideal urbanístico “[...] correspondente à tendência continuamente manifesta no século XIX de enobrecer necessidades técnicas por meio de objetos artísticos” (p. 49). Haussmann é o urbanista do capital por excelência, pois, captando os anseios da burguesia, edifica, em Paris, uma geografia do capital (imperialista), que fará longa carreira em todo mundo.

As instituições do poder laico e espiritual da burguesia deveriam encontrar sua apoteose no enquadramento das avenidas; antes de 
sua conclusão, estas eram recobertas por lonas e descerradas qual monumentos. - A eficiência de Haussmann insere-se no imperialismo napoleônico. Este favorece o capital financeiro. Paris vive o auge da especulação. [...] Haussmann tenta reforçar sua ditadura colocando Paris sob um regime de exceção. Em 1864, em um discurso na Câmara, expressa seu ódio pela população desenraizada da grande cidade. Esta cresce constantemente devido aos próprios empreendimentos de Haussmann. O aumento dos aluguéis impele o proletariado para os subúrbios. Com isso, os bairros de Paris perdem sua fisionomia própria. Surge o ‘cinturão vermelho’ operário. Haussmann denomina a si mesmo de 'artista demolidor'. Sentia-se predestinado à sua obra, fato que enfatiza em suas memórias. Entretanto, provoca nos parisienses estranhamento em relação à sua cidade. Nela não se sentem mais em casa. Começam a tomar consciência do caráter desumano da grande cidade (Benjamin, 2009, p. 49).

As intervenções urbanas de Haussmann reafirmam que a contabilidade espaço-temporal do sistema do capital, focada na valorização do valor, efetiva o conectivo entre o intérieur e a haussmannização por meio do estranhamento de todo o espaço produzido. Desse modo, a reprodução do capital consegue romper cada vez mais as barreiras espaciais da produção mercantil ao passo que decreta a extinção das barricadas pelo alargamento das ruas e a proximidade que agora estabelecem entre o aparelho repressor do estado e os bairros operários (Benjamin, 2009, p. 50) - e fomenta a sustentação ideológica de sua práxis / discurso.

A haussmannização convive com o período em que as passagens estão em decadência e, contraditoriamente, faz florescer, de forma ainda mais intensa, o legado do instante dialético das passagens: abrir espaço para o 'baile' das mercadorias.

David Harvey (2015) consegue captar esse processo a partir da vinculação entre capital financeiro, interesse imobiliário e Estado, vinculados, por sua vez, à distribuição do produto social na forma dos juros, aluguel e impostos. Adverte o autor que o caráter da dimensão urbana da haussmannização vincula-se com a relação entre distribuição e produção determinada por Marx, tendo grande importância para a compreensão do funcionamento do capitalismo.

Nesse caso, o posicionamento resulta em larga medida do fato de que as novas relações espaciais (tanto externas quanto internas) foram criadas a partir de uma coalizão entre Estado, capital financeiro 
e interesse imobiliário, e que cada um teve que passar por um doloroso ajuste ao outro para que as ações necessárias pudessem ocorrer no processo de transformação urbana (Harvey, 2015, p. $143-144)$.

Além dos aspectos de racionalização do espaço segundo a lógica mercantil, Harvey (2015) chama a atenção para a íntima relação entre as transformações em marcha, capitaneadas pelo redimensionamento escalar haussmanniano no espaço de Paris, e os processos de unificação do mundo pela monetização e intercâmbio de mercadorias.

Haussmann aceita a ideia de que o "[...] crédito universal era a saída para o progresso econômico e a reconciliação social” (Harvey, 2015, p. 163), sendo fundamental fomentar uma ordenação espacial específica de modo a potencializar a materialização dessa ideia. Por essa razão Harvey (2015) classifica como espetacular a mobilização do fluxo de capital para transformar o meio ambiente construído na Paris do Segundo Império, implicando a objetivação da relação direta entre a criação e modificação do espaço (produção) e a absorção dos excedentes de capital, além dos aspectos políticos (dominação e controle de conflitos de classe muito presentes na história recente da metrópole). "Os excedentes do capital que, do contrário, ficariam desvalorizados, poderiam ser absorvidos por meio de expansões geográficas e de deslocamentos espaço-temporais” (Harvey, 2013, p. 22).

O processo de produção das passagens parisienses - bem como o processo de haussmannização - retrata a concreticidade da ampliação do ciclo e mobilidade do capital, daí os deslocamentos espaço-temporais (ajuste espacial) sinalizados por Harvey (2013; 2015).

Acompanhar parte do percurso benjaminiano nas / das passagens para compreender a produção do homem nessa geografia da circularidade do capital faz-se necessário, tendo em vista a extensão da pesquisa e os temas que aborda.

Geografia das passagens: o espaço-tempo alienado para o capital

Os boulevards, os magasins de nouveautése, as passagens, durante o século XIX, foram a feição característica de espacialização do capital em Paris. Ligadas diretamente à expansão industrial e, consequentemente, à expansão da forma valor, adequavam-se à circularidade capitalista entre 
os fins do século XVIII e meados do século XIX. As passagens dizem respeito a

[...] uma hermenêutica dos espaços fantasmáticos da cidade de Paris, cuja infra-estrutura é a mercadoria. Passagens e arcadas são templos do consumo, catedrais profanas onde se instalam as exposições universais e a produção mercantil; nelas se exibem objetos em série e artefatos das moradas e de seus interiores, interiores que são um mundo particular onde o burguês louis-philippard se recolhe em sua paixão fetichista, junto a suas coleções. Fechado entre quatro paredes, coleciona para indenizar-se de 'tão poucos rastros que a cidade deixa para a vida privada'. Os interiores são o brilho e o esplendor com que se envolve a sociedade produtora de mercadorias, onde se desenvolve o sentimento ilusório da segurança; o homem desrealizado faz de seu domicílio um refúgio, do interior burguês e da loggia ele contempla o theatrum mundi (Matos, 2009, p. 1123).

Tanto no âmbito temporal, ordenada pela contabilidade do tempo especificamente capitalista; quanto no âmbito espacial, cujo flanar que as passagens permitem são a captura dos homens concretos no plano da divisão social e territorial do trabalho; as passagens e sua suntuosidade morfológica, calcada nas construções apoiadas em ferro e em vidro, proporcionavam o fluir da valorização do valor desde o habitat - 'estojo' do homem-estojo - as ruas e o mundo, com as exposições universais.

Flanar pelas passagens oferecia abrigo para proteção do mau tempo, ao mesmo tempo em que abrigava as boutiques, galerias, abrindo caminho a lugares. Por exemplo, a Passage de l'Opéra (Figura 1) ligava galerias e Boulevards à Opéra (p. 76) e, como passagem, servia para demolir os resquícios da circulação simples $(\mathrm{M}-\mathrm{D}-\mathrm{M})$.

O espaço-tempo e as determinações da flânerie estavam postas na processualidade da regulação capitalista. "Evocava-se o 'gênio dos jacobinos e dos industriais’ e atribuía-se este dito a Luís Felipe: Deus seja louvado e minhas boutiques também. As passagens como templo do capital mercantil” (Benjamin, 2009b, p. 80). 


\section{Figura 01 - Passage-Opera.}

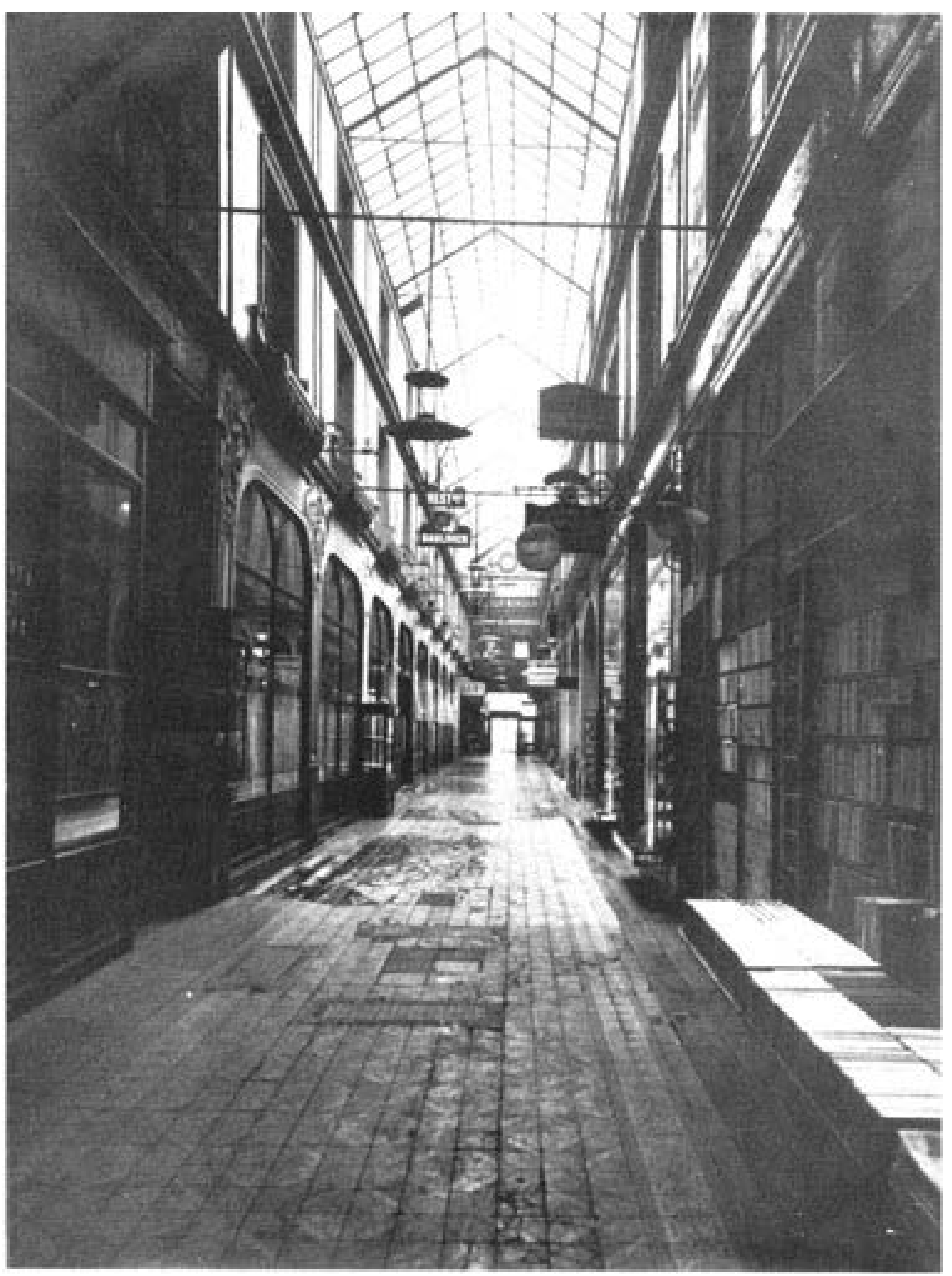

Fonte: <http://martinaderen.com/arte/construir-caminando-francis-alys-y-el-paseo-urbano/>. 
As lojas de departamentos - os grands magasins - datam do Segundo Império e se desenvolvem desde 1870. As bolsas de valores já integravam a paisagem parisiense; o capital mercantil, o capital industrial e o capital financeiro coabitam no mesmo espaço, as passagens e as ruas de Paris mostram a unificação das frações do capital, característica do imperialismo.

Enquanto o flanar tomava conta das passagens e ruas, garantindo as preces e orações no templo do capital e das mercadorias, era possível especular sobre as ações das ferrovias no período de Luís Felipe. Citando Rodenberg (1867), Benjamin chama a atenção para o "flanar" do capital especulativo: "Da mesma origem [isto é, da casa dos Rothschild] provém Mirès, de admirável eloquência, que só precisava abrir a boca para convencer seus credores que a perda é um ganho [...]" (2009b, p. 82).

O pesquisador também expõe sobre o pregão: na "[...] rua dos vendedores de boletins da bolsa. Na alta: 'A alta da bolsa'. Na baixa: 'As variações da bolsa'. O termo baixa foi proibido pela polícia” (Benjamin, 2009b, p. 82). Nas passagens já se tornava possível a substância discursiva de o capital - na perspectiva ideológica - se impor.

As mulheres, que não podiam entrar na Bolsa de Valores, ficavam na entrada à procura de informações para repassar ordens aos seus corretores. Desde as passagens, a mobilidade foi sempre mais limitada aos seres humanos do que para o capital. O télos espaço-temporal das passagens resistiu aos séculos que viriam.

Passagens com galerias cobertas, de iniciativa privada, datadas de 1820 - Passage Viollet e a Passage des deux Pavillions - abrigavam boutiques que a moda fez prosperar; a moda integra-se à espacialidade. A iniciativa privada também estimulou a criação das cites, ruas curtas ou sem saídas, construídas, com despesas comuns, por um sindicato de proprietários (Dubech [1926] In: Benjamin, 2009b, p. 84 - 85).

As passagens permitiam conexões de muitas ruas, atalhos que serviam de proteção ao abrigo do tempo ruim ou, com a sua iluminação a gás, ofereciam brilho necessário ao flanar noturno; as passagens eram a preparação das metrópoles para um tempo que nunca dorme, saciando, do ponto de vista quantitativo, a contabilidade do Cronos (geralmente associado ao tempo e sua força na mitologia grega) capitalista.

O comércio e o tráfego são os dois componentes da rua. Ora, nas passagens, o segundo está praticamente extinto; o tráfego aí é 
rudimentar. A passagem é apenas rua lasciva do comércio, só afeita a despertar os desejos. Mas como nesta rua os humores deixam de fluir, a mercadoria viceja em suas bordas entremeando relações fantásticas como um tecido ulcerado. - O flâneur sabota o tráfego. Ele também não é comprador. É mercadoria. Pela primeira vez na história, com a criação das lojas de departamentos, os consumidores começam a sentir-se como massa. (Antigamente, só a escassez lhes dava esta sensação). Com isso, aumenta consideravelmente o elemento circense e teatral do comércio (Benjamin, 2009b, p. 86).

Outra novidade que surge sob o ímpeto dos processos acumulativos que trazem à tona as passagens são as ruas-galerias (Figura 2). Fourier escreveu sobre elas como um método de comunicação interna - das conexões espaço-temporais mercantis -; uma facilidade de ir para todos os lados ao abrigo das intempéries, frequentar bailes durante as geadas, usar sapatos sem se preocupar com a lama ou o frio (2009b, p. 87).

Figura 2 - Ruas-Galerias (Paris).

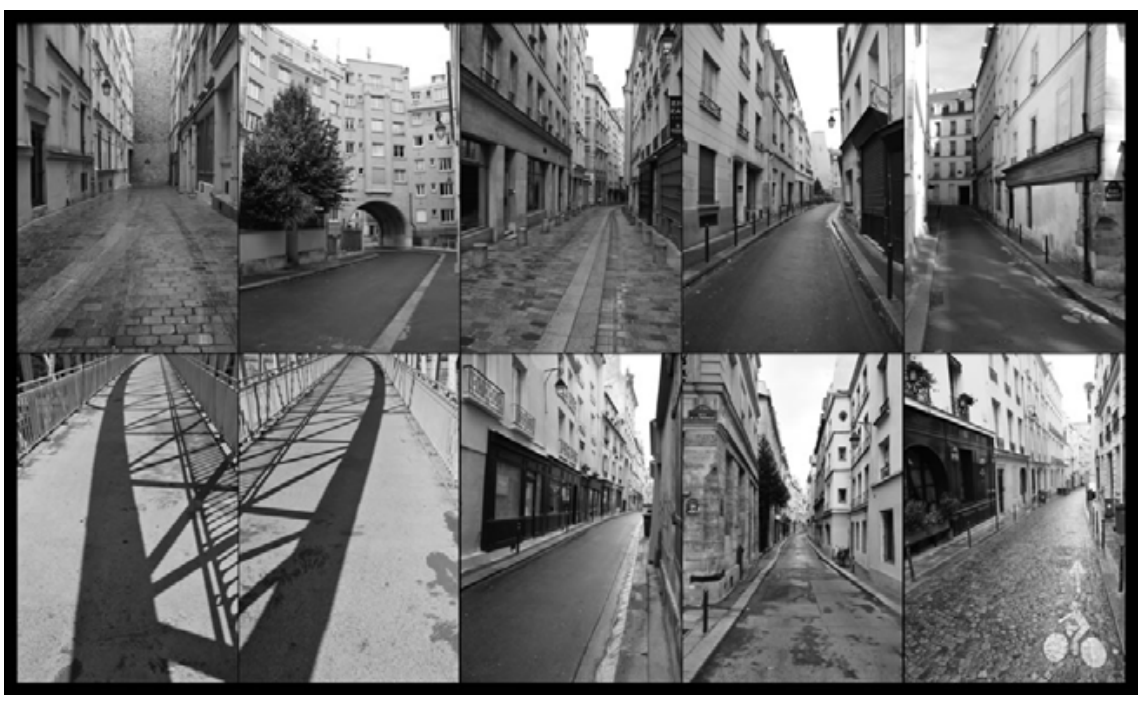

Fonte: <http://www.studium.iar.unicamp.br/34/2/>.

O comércio como senhor e rei do mundo, na alusão resgatada por Benjamin de um diálogo entre personagens do texto de Barière ([1855]; 2009 , p. 89 -90), precisa de vassalos, e esses, por sua vez, de pintura, 
escultura, música, arte, que as ruas-galerias das passagens podiam abrigar na constituição de suas vitrines. Calicots ${ }^{3}$, vitrines e os preços fixos ao lado das mercadorias inovam o mundo do comércio da moda. Apelos do ponto de vista do desejo e do onírico que os comerciantes parisienses converteram ao seu favor nas vendas de mercadorias. As passagens despertam desejos recônditos ancorados nas fantasmagorias da mercadoria.

As ruas-salões - as mais largas entre as ruas galerias - são bem ornamentadas e têm forma suntuosa, atraindo um grande número de transeuntes que começa a circular depois da limpeza. Nas galerias, é proibida a entrada de indivíduos sujos e portadores de fardo, sendo também proibido escarrar ou fumar (Benjamin, 2009b, p. 94). A proletarização do flâneur já bate às portas do cigarro negado.

Todo o horizonte das ruas e das passagens com suas galerias, boutiques, magasins e lojas de departamento é a vista a alcançar o desenvolvimento do ciclo do capital, sua mobilidade e divisão do trabalho características.

\section{Considerações finais}

As reflexões expostas, baseadas na pesquisa desenvolvida por Walter Benjamin (2009) sobre as passagens parisienses, têm a intenção de levantar a utilidade da construção benjaminiana para a compreensão do espaço-tempo no âmbito do sistema do capital e de sua geografia.

É possível perceber o quão útil é tal empreitada por possibilitar o agenciamento de elementos teórico-metodológicos para a compreensão da modernidade capitalista e suas expressões espaciais, que tomaram as ruas de Paris por meio das suas passagens e das formas haussmannianas impostas na ordenação da capital do capital.

Os apontamentos realizados por Benjamin (2009) demonstram bem a estruturação de uma lógica espaço-temporal convertida à funcionalidade mercantil. Nesse aspecto traz consigo as tensões que a mercadoria contém em seu processo produtivo, um espaço-tempo e uma geografia plasmada pela alienação, pelo valor de troca, pela fantasmagoria e pelo consumo. $\mathrm{O}$ mundo acaba por se configurar sob os mesmos pressupostos das passagens

\footnotetext{
${ }^{3}$ Empregado masculino das lojas de departamentos, boutuques, magasins, do comércio parisiense (Benjamin, 2009, p.
} $92-93)$. 
parisienses: na captura do espaço-tempo a serviço do mais-valor (do lucro), cuja geografia que se efetiva servil ao cálculo capitalista.

Abre-se, entretanto, a possibilidade da compreensão que levanta a ruptura com a ordenação produzida pelo capital. Ao expor a crítica àquilo que vem se constituindo espaço-temporalmente, Benjamin (2009) não perde de vista seu compromisso com a tradição dos oprimidos e, com isso, mantém a indicação da urgente tarefa de criar um estado de emergência. Ao geógrafo cabe produzir uma geografia que contribua com essa tarefa.

Notas

1. O presente artigo é parte da reflexão desenvolvida no terceiro capítulo da tese de doutorado do autor: $\mathrm{O}$ (des)conceito de Homem na leitura do espaçotempo postulado na Geografia Humana - os enigmas de uma Geografia Humana sem Homens. Defendida no ano de 2015 junto ao Programa de PósGraduação em Geografia da Universidade Federal de Sergipe - PPGEO/UFS. Orientação da Profa. Drạ. Alexandrina Luz Conceição.

2. "Fantasmagoria é o processo de produção capitalista em geral que se apresenta aos homens que o realizam como poder da natureza" (Tiedemann apud Benjamin, 2009, p. 23)

3. Diz respeito ao conjunto de intervenções urbanísticas implementadas em Paris, a partir dos projetos do Barão Haussmann, no período de Napoleão III (Benjamin, 2009)

4. Na informação da nota de rodapé $n$ - 2, da página 39, consta que os magasins de nouveautés ofereciam uma seleção completa de mercadorias de diversas especialidades. Estendendo-se por vários andares tais estabelecimentos empregavam uma grande quantidade de trabalhadores. $O$ primeiro foi inaugurado no ano de 1793.

5. Foi Rei da França de 1830 até 1848. Na Ideologia Alemã o contexto referencial da Revolução de Julho é esclarecido: refere-se à revolução francesa de julho de 1830, que depôs o Rei Bourbon Carlos X e alçou ao trono Luís Felipe de Orléans, conhecido como "o rei burguês". Seu reinado (a Monarquia de Julho), caracterizado por alterações de caráter liberal na constituição restauracionista de 1814, duraria até a revolução de 1848 (Marx; Engels, 2007, p. 558).

6. Refere-se à vida privada no interior das habitações francesas: hábitos e habitats (Benjamin, 2009). 
7. Ocupou o cargo de primeiro ministro da França entre 1847-1848, exercendo considerável influência sob o reinado de Luís Felipe (Benjamin, 2009).

8. Empregado masculino das lojas de departamentos, boutuques, magasins, do comércio parisiense (Benjamin, 2009, p. 92 - 93).

\section{Referências}

BENJAMIN, W. Passagens. Belo Horizonte: Editora UFMG; Imprensa Oficial do Estado de São Paulo, 2009.

HARVEY, D. Condição pós-moderna. 10a Ed. São Paulo: Edições Loyola, 2001.

HARVEY, D. Os limites do capital. São Paulo: Boitempo Editorial, 2013.

HARVEY, D. Paris: capital da modernidade. São Paulo: Boitempo Editorial, 2015.

MARX, K; ENGELS, F. Ideologia Alemã. São Paulo: Boitempo Editorial, 2007.

MARX, K. Grundrisse. São Paulo: Boitempo Editorial, 2011.

MARX, K. As lutas de classes na França de 1848 a 1850. São Paulo: Boitempo Editorial, 2012.

MARX, K. O Capital: crítica da economia política. Livro I. São Paulo: Boitempo Editorial, 2013.

MATOS, O. C. F. Aufklärung na metrópole: Paris e a Via Láctea. In: BENJAMIN, W. Passagens. Organização da edição brasileira WilliBolle; posfácios de WilliBolle e Olgária Chain Féres Matos. Belo Horizonte: Editora UFMG; São Paulo: Imprensa Oficial do Estado de São Paulo, 2009; p. 1123 a 1140.

MÉSZÁROS, I. O desafio e o fardo do tempo histórico. São Paulo: Boitempo Editorial, 2007.

TIEDEMANN, R. Introdução à edição alemã. In: BENJAMIN, W. Passagens. Organização da edição brasileira WilliBolle; posfácios de WilliBolle e Olgária Chain Féres Matos. Belo Horizonte: Editora UFMG; São Paulo: Imprensa Oficial do Estado de São Paulo, 2009; p. 13 a 33.

Wagnervalter Dutra Júnior - Possui graduação em Geografia pela Universidade Estadual do Sudoeste da Bahia e especialização em Ciências Ambientais pela mesma universidade. É Mestre e Doutor em Geografia pela Universidade Federal de Sergipe. Atualmente é professor da Universidade do Estado da Bahia.

Recebido para publicação em 15 de fevereiro de 2016 Aceito para publicação em 21 de março de 2016 
